Modalidades de Lavado de Dinero y Activos

Cano Castaño, Miguel Antonio;

"Modalidades de Lavado de Dinero y

Activos. Prácticas contables para su detección y prevención"; $1^{\text {a }}$. edición; Ecoe Ediciones; 2001; 142 páginas; Bogotá Colombia. ISBN: 9586482847

\title{
Modalidades de Lavado de Dinero y Activos
}

Lavar es el proceso que consiste en purificar o quitar las manchas de al. guna cosa. El concepto de lavado de dinero o lavado de activos, se refiere a la actividad de encubrir el origen de los fondos que se obtienen mediante actividades ilegales. La diferencia entre ambos es que en el primer caso el dinero proviene del narcotráfico y el lavado de activos es la acción de una apariencia legal a los recursos provenientes de origen ilícitos.

El autor ha realizado una serie de investigaciones periodísticas donde muestra la manera de cómo el lavado de dinero es una práctica que se realiza desde hace varios años, que perjudica no a una nación sino también que tiene implicaciones globales. Se origina mediante algunas actividades ilícitas como el tráfico de drogas, corrupción, fraude fiscal, contrabando, trabajo ilegal, etc.

Se vive en un mundo globalizado en donde el crimen organizado se adapta a la sofisticación de los avances tecnológicos, ya que tienen mayor acceso a la velocidad y facilidad de las modernas finanzas electrónicas, con el fin de burlar normas y controles, atentado con la comisión de delitos graves de amplia repercusión social. Por ejemplo, pueden mencionarse los casinos virtuales que según las investigaciones, Costa Rica se ha convertido en el centro mundial, con aproximadamente 100 negocios; las apuestas deportivas, que ha cobrado fuerza especialmente en Venezuela, Curazao, Granada, Aruba, Antigua, Bermuda, Costa Rica, República Dominicana, Bélgica y Belice. La modalidad de estos negocios es que el cliente antes de apostar, debe de abrir una cuenta bancaria. Así, el uso de loterías, juegos de azar y dólares en alcanfor son métodos utilizados, por ejemplo en Panamá; los lavadores de dinero compran billetes de lotería ganadores del primer premio y utilizan alcanfor para aromatizar los dólares y así ocultar el olor a cocaína que se le impregna al dinero. 
La lucha contra el lavado es sumamente amplia, existen organismos gubernamentales que de manera continua, estudian y analizan posibles indicios de este delito alrededor del globo. La idea no solo es ponerle fin al lavado de dinero, sino que al criminal y sus negocios mal habidos. Ya que con esto se interrumpe el flujo de capital que utiliza como inversión.

Como un mecanismo de control, la contabilidad es una herramienta en donde puede detectarse cualquier anomalía en el mundo empresarial y como recurso de prevención del lavado de dinero y de otros activos.

El conocimiento del cliente es fundamental en la prevención del lavado de dinero. Aunque no debe ser el cliente externo, sino a todos y cada uno de los funcionarios, proveedores y dueños que hacen parte de una organización. Por esta razón, es necesario aplicar los procedimientos adecuados para obtener información completa sobre las actividades y datos del cli. ente, además de conocer y analizar su operatividad habitual en relación con la entidad para efectos de determinar incoherencia y otras pautas sospechosas.

Como medida de prevención, se recomienda a los organismos de control, vigilancia e investigación, acudir a técnicas de auditoría para que detecten y comprueben operaciones ilícitas relacionadas con el lavado y delitos financieros. 